\title{
Perovskite-Type $\mathrm{LaFeO}_{3}$ and $\mathrm{LaFeO}_{3}$-CNTs Nanocrystals as Active Anode for Methanol Oxidation in Alkaline Solutions
}

\author{
Mehri-Saddat Ekrami-Kakhki ${ }^{1}$, Zahra Yavari ${ }^{2}$, Jilla Saffari ${ }^{3}$ and Seyed Ali Ekrami-Kakhki ${ }^{4}$ \\ 1. Nano Technology Laboratory, Engineering Department, Esfarayen University of Technology, Esfarayen, Iran \\ 2. Department of Chemistry, University of Sistan and Baluchestan, Zahedan, Iran \\ 3. Young Researchers and Elite Club, Zahedan Branch, Islamic Azad University, Zahedan, Iran \\ 4. Department of Engineering, Tafresh University, Tafresh, Iran
}

\begin{abstract}
In the current study, perovskite type $\mathrm{LaFNPs}\left(\mathrm{LaFeO}_{3}\right.$ nanoparticles) were prepared by a rapid microwave-assisted co-precipitation method and their presence was confirmed by XRD, EDX and SEM techniques. LaFNPs and LaFNPs-CNTs

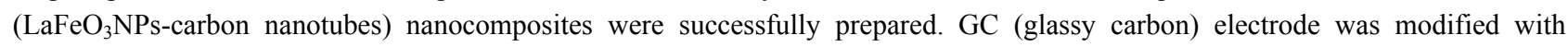
LaFNPs and LaFNPs-CNTs for methanol electrooxidation. The electrocatalytic activity of LaFNPs and LaFNPs-CNTs nanocatalysts toward methanol electrooxidation was examined through cyclic voltammetry and chronoamperometry methods. The effect of some experimental factors such as methanol, LaFNPs amounts, electrolyte concentrations and scan rate was studied. The catalytic activity of LaFNPs-CNTs and LaFNPs nanocatalysts was compared with each other. According to the electrochemical investigations, LaFNPs nanocatalyst had a considerable activity for methanol electrooxidation in comparison to LaFNPs nanocatalyst.
\end{abstract}

Key words: Nanocomposite, nanocatalyst, methanol electrooxidation.

\section{Introduction}

Direct methanol fuel cells are attracting more and more attention as renewable and clean power sources for electric vehicles and portable electronic devices. Methanol as a liquid fuel has unique advantages in comparison to hydrogen, such as easy producing, storage and transportation, simple structure and high energy density. Also, methanol has good kinetics of oxidation at low temperatures compared to other alcohols. It can be oxidized completely to $\mathrm{CO}_{2}$ with maximum transfer of electrons. Thus, methanol oxidation has been investigated extensively over the past several decades. Noble metals, especially Pt-based [1] and Pt Ru bimetallic systems [2] show excellent activities toward methanol electrooxidation,

Corresponding author: Mehri-Saddat Ekrami-Kakhki, Ph.D., assistant professor, research fields: nanocatalysts, nanocomposites and fuel cells. E-mail: ekrami@esfarayen.ac.ir. but the price of pure platinum is relatively high. Furthermore, the intermediates produced during the methanol oxidation such as $\mathrm{CO}$ (carbon monoxide) would poison the noble metal sites [1] and this cause the deterioration in the performance of noble metal-based fuel cell electrodes. Such poisoning phenomenon can be also avoided by using electronically conducting mixed oxides as anode materials. Though the oxides of V, Fe, Ni, In, Sn, La and $\mathrm{Pb}$ were earlier used as anode materials [3]. In recent years, studies on various transition metal mixed oxides have shown that the perovskite oxides can be used as fuel cell electrodes at high temperatures instead of noble metals [4-7]. Perovskite-type solids especially with general formula, $\mathrm{ABO}_{3}$ with different combinations of $\mathrm{A}$ and $\mathrm{B}$ cations $(\mathrm{A}=$ rare earth metals, $\mathrm{B}=$ transition metals) have been considered promising catalytic materials for increasing anodic reaction kinetic in direct alcohol fuel cells. They can 
be used in important processes [8-10] such as, electrochemical evolution/reduction of oxygen, oxidation of alcohols [11, 12], reduction of nitrogen oxides and chemical oxidation of $\mathrm{CO}$ and hydrocarbons [13, 14] etc. Recently, several studies on perovskite oxides with a large amount of oxygen vacancies and excellent electrical conductivities have shown that these compounds can be used as electrodes in direct alcohol fuel cells [15-18].

CNTs (carbon nanotubes) are considered an attractive supporting material due to nanometer size, large surface to volume ratio, high electronic and thermal conductivity, in addition to good mechanical and chemical stability [19-21].

In this work, we have prepared perovskite-type $\mathrm{LaFeO}_{3}$ and $\mathrm{LaFeO}_{3}-\mathrm{CNTs}$ nanocatalysts and used them for electrocatalysis of methanol oxidation in alkaline media. Alkaline medium was chosen since these materials are unstable in acid medium. The electrochemical characterization of LaFNPs and LaFNPs-CNTs nanocatalysts toward methanol oxidation was investigated by cyclic voltammetry and chronoamperometry techniques. The effect of some experimental factors on the anodic current density and potential of methanol electrooxidation was investigated and the optimum conditions were determined.

\section{Experimental}

\subsection{Materials}

Nafion@117 solution was purchased from Merck and used as received. $\mathrm{LaCl}_{3} \cdot 7 \mathrm{H}_{2} \mathrm{O}, \mathrm{FeCl}_{3} \cdot 6 \mathrm{H}_{2} \mathrm{O}$, $\mathrm{NaOH}$, methanol and octanoic acid were purchased from Merck, and used without further purification. MWCNTs (multiwall carbon nanotubes), with nanotube diameters, $\mathrm{OD}=20-30 \mathrm{~nm}$, wall thickness $=$ $1-2 \mu \mathrm{nm}$, length $=0.5-2 \mu \mathrm{m}$ and purity $>95 \%$ was purchased from Aldrich. All solutions were prepared using doubly distilled water. Purified $\mathrm{N}_{2}$ (99.9\%) was used without further treatment.

\subsection{Instrumentation}

EDX and SEM images were got by Philips XL30 apparatus. The ultrasonic apparatus with Eurosonic 4D model was used for synthesis of the nanocomposites. The XRD spectra were obtained by Philips analytical PC-APD apparatus with graphite monochromatic $\mathrm{Cu} \mathrm{K} \alpha$ radiation $(\lambda=1.54056 \AA)$. The centrifuge apparatus with Sigma 101 model was used for separation of the precipitate. Electrochemical investigations were done by POTENTIOSTAT GALVANOSTAT AUTOLAB controlled by a personal computer.

\subsection{Preparation of $\mathrm{LaFeO}_{3}$ Nanocatalysts}

Perovskite oxide nanoparticles with the molecular formula of $\mathrm{LaFeO}_{3}$ were synthesized by a microwave-assisted co-precipitation method using octanoic acid as surfactant. Preparation of $\mathrm{LaFeO}_{3}$ nanocatalyst was as follows, at first, $20 \mathrm{~mL}$ of $\mathrm{FeCl}_{3} .6 \mathrm{H}_{2} \mathrm{O} 0.2 \mathrm{M}$ and $20 \mathrm{~mL}$ of $\mathrm{LaCl}_{3} .7 \mathrm{H}_{2} \mathrm{O} 0.2 \mathrm{M}$ aqueous solutions were mixed in a beaker and stirred until the complete solving. And $2 \mathrm{~mL}$ of octanoic acid was added as surfactant to the resulted orange solution. Then, $25 \mathrm{~mL}$ of $\mathrm{NaOH}$ solution was added very slowly and drops wise to the mixture until the $\mathrm{pH}$ of 7-8 and preparation of the brown precipitate. After complete precipitation, the liquid precipitate was transferred to the microwave infrared irradiation $(900$ $\mathrm{W} / 180^{\circ} \mathrm{C}$ ) for $6 \mathrm{~min}$. After cooling, the mixture was centrifuged with 3,000 rpm for $15 \mathrm{~min}$ and washed by ethanol and water for several times. The product was calcinated at $800{ }^{\circ} \mathrm{C}$ in the furnace for $4 \mathrm{~h}$ to lose all its residual organic materials. The prepared $\mathrm{LaFeO}_{3}$ nanocatalysts were kept for characterization.

\subsection{Electrochemical Investigations}

Electrochemical measurements have been done with a POTENTIOSTAT GALVANOSTAT AUTOLAB controlled by a personal computer. A conventional three-electrode cell with platinum and a 
SCE (saturated calomel electrode) as the counter and reference electrodes, respectively was used for electrochemical investigation at room temperature. All potentials were reported with respect to the reference electrode. The GC (glassy carbon) electrode with 2 $\mathrm{mm}$ of diameter was used as the working electrode. The working solution was $\mathrm{N}_{2}$-saturated $1.75 \mathrm{M}$ of methanol and $1.5 \mathrm{M} \mathrm{NaOH}$. All experiments were performed under nitrogen atmosphere at room temperature. All glassware was thoroughly cleaned with freshly prepared aqua regain $\left(3: 1 ; \mathrm{HCl} / \mathrm{HNO}_{3}\right)$ and rinsed comprehensively with double distilled water prior to use. Scan rate for all the experiments was $100 \mathrm{mV} \mathrm{s}^{-1}$.

\subsection{Preparation of the Electrode}

To prepare GC/LaFNPs electrode, $2 \mathrm{mg}$ of $\mathrm{LaFeO}_{3}$ nano-powder and $5 \mu \mathrm{L}$ Nafion were dispersed in 0.5 $\mathrm{ml}$ of double distilled water by sonication for $120 \mathrm{~min}$ to obtain a suspension. Then $5 \mu \mathrm{L}$ of the prepared suspension was spread by pipette onto the glassy carbon substrate. The subsequent evaporation of the solvent led to the formation of the deposited catalyst layer. In order to prepare GC/LaFNPs-CNTs electrode, $2 \mathrm{mg}$ of $\mathrm{LaFeO}_{3}$ nanocatalyst, $5 \mu \mathrm{L}$ Nafion and $1 \mathrm{mg}$ MWCNTs were dispersed in $0.5 \mathrm{~mL}$ of double distilled water and ultrasonicated for $120 \mathrm{~min}$ to obtain a suspension. $5 \mu \mathrm{L}$ of the prepared suspension was spread by pipette onto the glassy carbon substrate. The subsequent evaporation of the solvent led to the formation of $\mathrm{LaFeO}_{3}-\mathrm{CNTs}$ layer.

\section{Results and Discussion}

\subsection{Characterization of $\mathrm{LaFeO}_{3}$ Nanocatalyst}

SEM image of $\mathrm{LaFeO}_{3}$ nanoparticles was shown in Fig. 1A. As seen in Fig. 1A, LaFNPs were very homogenate and sphere like with the particle size of about $71.96 \mathrm{~nm}$. The XRD analysis showed clearly the pattern corresponding to perovskite-type $\mathrm{LaFeO}_{3}$ (JCPDS File No. 37-1493), which crystallizes in the orthorhombic system with a main diffraction peak at $\mathrm{d}$
$=2.77 \AA$ ((l 2 1 1 ) plane) (Fig. 1B). The following Eq. (1) [22] was used for determining the lattice parameters:

$$
\frac{1}{d^{2}}=\frac{\hbar^{2}}{a^{2}}+\frac{k^{2}}{b^{2}}+\frac{l^{2}}{c^{2}}
$$

where $d$ was the distance between crystalline planes with Miller indices (hkl), also $a, b$ and $c$ were the lattice parameters. The lattice parameters of $\mathrm{LaFeO}_{3}$ nanocrystals were $a=5.58, b=7.84$ and $c=5.53 \AA$. The particle size of $\mathrm{LaFeO}_{3}$ nanocrystals was calculated with Debye-Scherrer equation [23]:

$$
D_{c}=\frac{K \lambda}{\beta \cos \theta}
$$

$D_{\mathrm{c}}$ is the particle size of $\mathrm{LaFeO}_{3}$ nanocrystals, $K$ is the shape factor which usually takes a value about $0.9, \lambda$ is the wavelength of the $X$-ray source used in XRD, $\beta$ is the breath of the observed diffraction line at its half-intensity maximum in radian and $\theta$ is the Bragg peak angle. The particle size of $\mathrm{LaFeO}_{3}$ nanocrystals was $73.55 \mathrm{~nm}$. The EDX spectrum of LaFNPs shown at Fig. $1 \mathrm{C}$ clearly revealed the presence of $\mathrm{La}$ and $\mathrm{Fe}$ elements. The element percent obtained from the EDX spectrum of LaFNPs was shown in the inset of Fig. 1C.

\subsection{Methanol Oxidation on LaFNPs and LaFNPs-CNTS Nanocatalysts}

Electrocatalytic property of LaFNPs and LaFNPs-CNTs nanocatalysts toward methanol electrooxidation was determined by cyclic voltammetry in $1.5 \mathrm{M} \mathrm{NaOH}$ and $1.75 \mathrm{M} \mathrm{CH}_{3} \mathrm{OH}$ aqueous solution. The typical cyclic voltammograms for $\mathrm{GC} / \mathrm{LaFNPs}$ and $\mathrm{GC} / \mathrm{LaFNPs}$-CNTs were shown in Fig. 2 and their catalytic activity toward methanol electrooxidation was compared with each other. The typical cyclic voltammograms for GC/Nafion and $\mathrm{GC} / \mathrm{LaFNPs}$ in $1.5 \mathrm{M} \mathrm{NaOH}$ and $1.75 \mathrm{M} \mathrm{CH}_{3} \mathrm{OH}$ were shown in Fig. 2A. As seen in Fig. 2A (a), GC/Nafion electrode did not show any catalytic activity toward methanol oxidation. Fig. 2A (b) showed the cyclic voltammogram of GC/LaFNPs in $1.5 \mathrm{M} \mathrm{NaOH}$. The anodic current obtained at potential greater than $0.7 \mathrm{~V}$ 

Methanol Oxidation in Alkaline Solutions
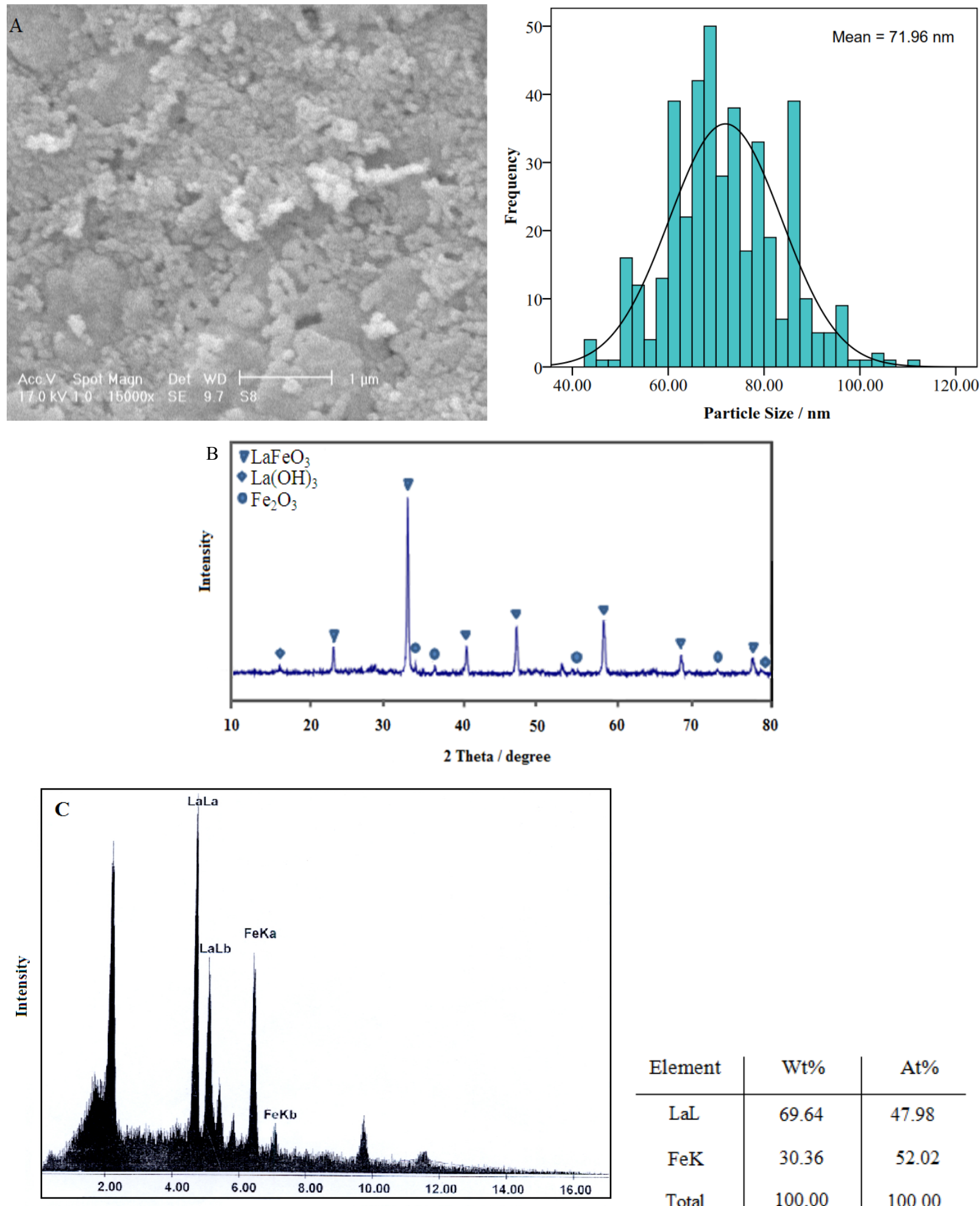

\begin{tabular}{c|r|r} 
Element & Wt $\%$ & At $\%$ \\
\hline LaL & 69.64 & 47.98 \\
FeK & 30.36 & 52.02 \\
Total & 100.00 & 100.00
\end{tabular}

Fig. 1 (A) SEM image; (B) XRD spectrum; (C) EDX with elemental composition of LaFNPs.

is due to the oxygen evolution reaction [24]. Cyclic voltammogram of GC/LaFNPs in $1.5 \mathrm{M} \mathrm{NaOH}$ and $1.75 \mathrm{M} \mathrm{CH}_{3} \mathrm{OH}$ was shown in Fig. 2A (c). As seen in
Fig. 2A (c), there was a large increase in current during the forward scan $\left(\mathrm{E}_{\mathrm{p}}=1.3 \mathrm{~V}\right)$ showing the high catalytic activity of LaFNPs nanocomposite for 

Methanol Oxidation in Alkaline Solutions

methanol oxidation. The onset potential of methanol oxidation on GC/LaFNPs electrode was observed at $0.8 \mathrm{~V}$. The characteristics of the $\mathrm{CV}$ curves are in agreement with other works [24-27]. This indicates that $\mathrm{LaFeO}_{3}$ is a good catalyst for methanol oxidation in alkaline solution. Similar to the mechanisms of methanol oxidation on Pt surface [28, 29] and on the perovskite $\mathrm{ARuO}_{3}$ surface [30], it seems that the possible reaction pathway on the perovskite $\left(\mathrm{LaFeO}_{3}\right)$ surface is as follows:

$$
\begin{gathered}
\mathrm{LaFeO}_{3}\left(\mathrm{H}_{2} \mathrm{O}\right)+\mathrm{CH}_{3} \mathrm{OH}(\mathrm{sol}) \rightarrow \\
\mathrm{LaFeO}_{3}\left(\mathrm{CH}_{3} \mathrm{OH}\right)+\mathrm{H}_{2} \mathrm{O} \\
\mathrm{LaFeO}_{3}\left(\mathrm{CH}_{3} \mathrm{OH}\right) \rightarrow \\
\mathrm{LaFeO}_{3}(\mathrm{CO})+4 \mathrm{H}^{+}+4 \mathrm{e} \text { (several steps) } \\
\mathrm{LaFeO}_{3}\left(\mathrm{H}_{2} \mathrm{O}\right) \rightarrow \\
\mathrm{LaFeO}_{3}(\mathrm{OH})+\mathrm{H}^{+}+\mathrm{e} \\
\mathrm{LaFeO}_{3}(\mathrm{CO})+\mathrm{LaFeO}_{3}(\mathrm{OH}) \rightarrow \\
\mathrm{CO}_{2}+\mathrm{H}^{+}+\mathrm{e}
\end{gathered}
$$

The cyclic voltammograms of GC/CNTs-Nafion and GC/LaFNPs-CNTs electrodes were shown in Fig. 2B. The typical cyclic voltammograms for GC/CNTs-Nafion in $1.5 \mathrm{M} \mathrm{NaOH}$ and $1.75 \mathrm{M}$ $\mathrm{CH}_{3} \mathrm{OH}$ was shown in Fig 2B (a). As seen in Fig. 2B (a), GC/CNTs-Nafion electrode did not show any catalytic activity toward methanol oxidation. Fig. 2B (b) showed the cyclic voltammogram of GC/LaFNPs-CNTs in $1.5 \mathrm{M} \mathrm{NaOH}$. Cyclic voltammogram of $\mathrm{GC} / \mathrm{LaFNPs-CNTs}$ electrode in 1.5 $\mathrm{M} \mathrm{NaOH}$ and $1.75 \mathrm{M} \mathrm{CH}_{3} \mathrm{OH}$ was shown in Fig. 2B (c). As observed in Fig. 2B (c), there was a large increase in the current density of the forward scan $\left(E_{p}=1.267 \mathrm{~V}\right)$. The onset potential of methanol oxidation on GC/LaFNPs-CNTs electrode was 0.565 V. Also the catalytic activities of GC/LaFNPs and $\mathrm{GC} / \mathrm{LaFNPs}-\mathrm{CNTs}$ electrodes toward methanol oxidation were compared with each other in Fig. 2C. As can be clearly seen, using CNT decreased the onset potential from 0.8 to $0.565 \mathrm{~V}$. Thus, LaFNPs-CNTs nanocomposite has better catalytic activity for methanol oxidation than LaFNPs nanocomposite.
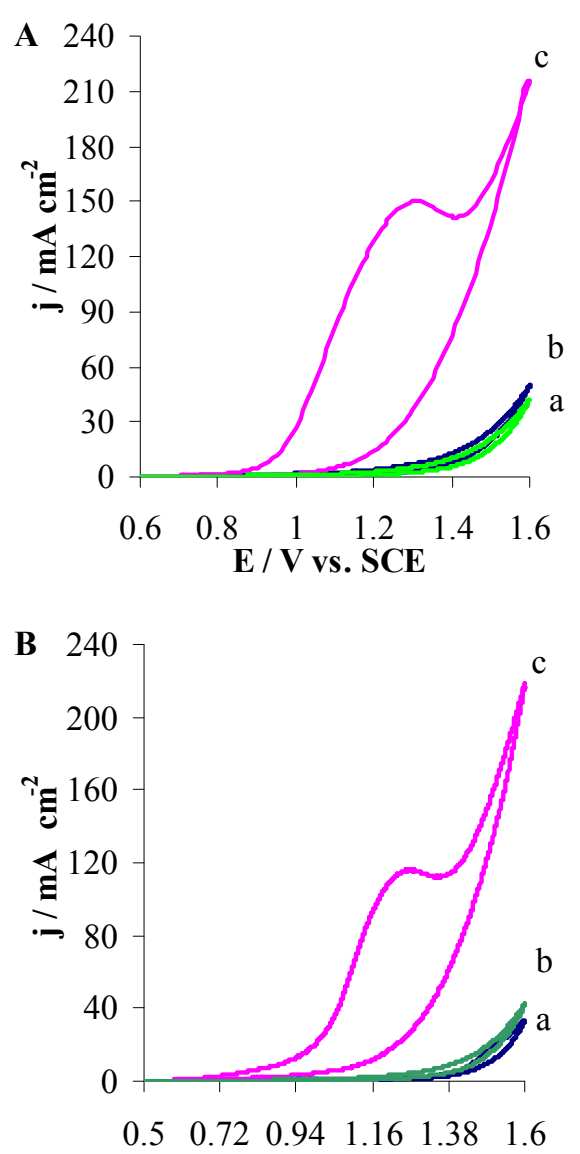

E / V vs. SCE

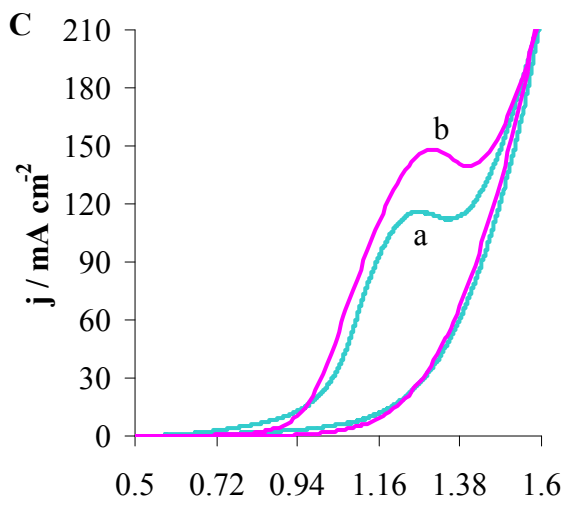

E / V vs. SCE

Fig. 2 Cyclic voltammograms of (A) $\mathrm{LaFeO}_{3}$ nanocatalyst in $1.5 \mathrm{M} \mathrm{NaOH}$ and $1.75 \mathrm{M} \mathrm{CH}_{3} \mathrm{OH}$ with a: GC/Nafion, b: GC/LaFNPs (in $\mathrm{NaOH} \quad 1.5 \mathrm{M}$ ) and e: GC/LaFNPs electrodes; (B) Cyclic voltammograms of LaFNPs-CNTs nanocatalyst in $1.5 \mathrm{M} \mathrm{NaOH}$ and $1.75 \mathrm{M} \mathrm{CH}_{3} \mathrm{OH}$ with a: GC/CNTs-Nafion, b: GC/LaFNPs-CNTs (in NaOH 1.5 M) and c: GC/LaFNPs-CNTs electrodes; (C) Cyclic voltammograms of a: GC/LaFNPs and b: GC/LaFNPs-CNTs electrodes in $1.5 \mathrm{M} \mathrm{NaOH}$ and $1.75 \mathrm{M}$ $\mathrm{CH}_{3} \mathrm{OH}$. 


\subsection{Determination of Surface Acid-Base Property} (PZC)

The electrocatalytic activity depends on the electronic and geometric factors $[31,32]$. The nature of the active sites and also the electronic structure of the catalyst can control the electronic factor, but the geometric factor depends on the real surface area and the number of the active sites. To determine the origin of the electrocatalytic activity and to optimize the electrode selection, separation of these two factors is essential. Separation can be obtained by evaluation of surface acid-base properties of the oxides in the aqueous solution and measurement of the actual surface area. The former is an intensive property that only depends on the nature of the active sites and does not depend on the surface area of the oxides. The surface acid-base property of the oxides is determined by measuring the $\mathrm{pH}$ of zero charge (PZC), the $\mathrm{pH}$ at which the oxide surface is electrically and chemically neutral. PZC is a measure of Lewis acidity [32]. The PZC value of LaFNPs was determined by acid-base potentiometric titrations [31]. A specific amount of LaFNPs was suspended in $10 \mathrm{~mL}$ of $\mathrm{KNO}_{3} 0.005 \mathrm{M}$ during $1 \mathrm{~h}$ of nitrogen bubbling to prevent any contamination from the $\mathrm{CO}_{2}$ present in the atmosphere. At first, the $\mathrm{pH}$ of the solution was 6.7 and it reached to 12 with addition of known amount of $0.1 \mathrm{M} \mathrm{NaOH}$. Then, the suspension was titrated with $0.1 \mathrm{M} \mathrm{HNO}_{3}$. The readings were recorded at each point after the $\mathrm{pH}$ became stable. The PZC of the oxide particles was obtained by determination of the intersection point of the titration curve in the presence and absent (blank solution) of LaFNPs. The titration curve to determine the PZC value for LaFNPs was shown in Fig. 3 and was found to be 11.25 that is much more than those reported for $\mathrm{La}_{2} \mathrm{NiO}_{4}, \mathrm{La}_{1.75} \mathrm{Sr}_{0.25} \mathrm{NiO}_{4}, \mathrm{La}_{1.5} \mathrm{Sr}_{0.5} \mathrm{NiO}_{4}$, $\mathrm{LaSrNiO}_{4}$ and $\mathrm{La}_{2-x} \mathrm{Sr}_{x} \mathrm{CuO}_{4}(0.0 \leq x \leq 0.4)$ [25]. It seems that, the PZC value of the oxide has influence on the electrocatalytic activity of the catalyst. In fact, the acidity of the surface $\mathrm{OH}$ group and also its bond strength to the active metal sites $(\mathrm{M}-\mathrm{OH})$ in the oxide decreases with increasing of the PZC value [33]. Thus, the higher values of PZC will show the higher reactivity of $\mathrm{OH}_{\text {ads }}$ because of the weakening of its bond strength. So, according to the PZC values, the rate of the methanol electro-oxidation at $\mathrm{LaFeO}_{3}$ nanoparticles would be greater than those reported before [25].

\subsection{Parameters Affecting on the Electrooxidation of Methanol on LaFNPS and LaFNPS-CNTS Nanocomposites}

\subsubsection{Effect of Methanol Concentration}

Fig. 4A and 4B showed the effect of methanol concentration on the anodic current density of methanol oxidation on GC/LaFNPs electrode. It can be clearly observed that increasing the methanol concentration up to $1.75 \mathrm{M}$ increased the anodic current density and, there was not any significant increase in the current density of methanol oxidation in methanol concentrations higher than $1.75 \mathrm{M}$. This effect was probably observed because of the saturation of active sites on the surface of the electrode. Also, this indicated further that the electrooxidation of methanol at modified electrode is controlled by diffusion process. Thus, to get a higher current density, this concentration of the methanol $(1.75 \mathrm{M})$ was selected

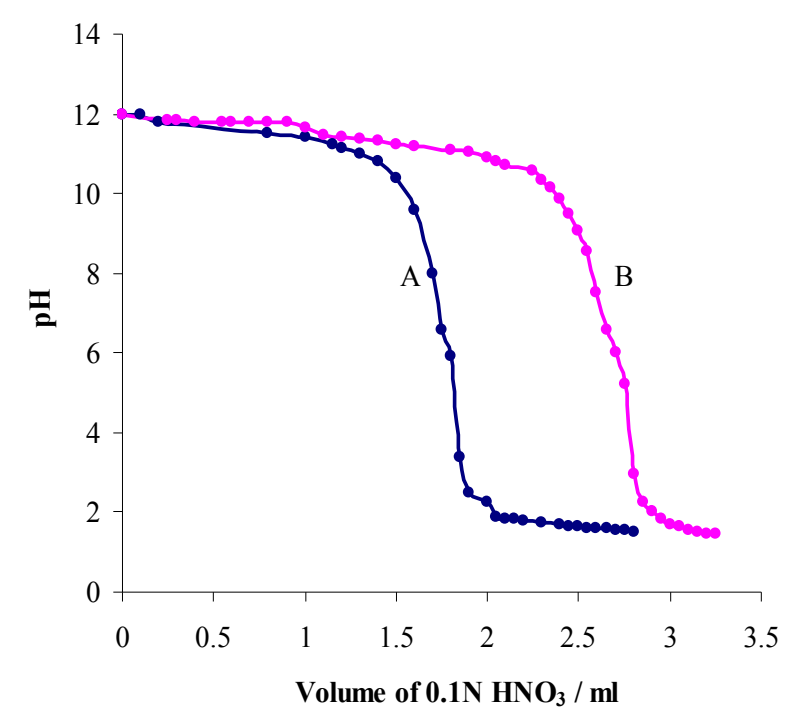

Fig. 3 The titration curve for determination of the PZC value of LaFNPs. 

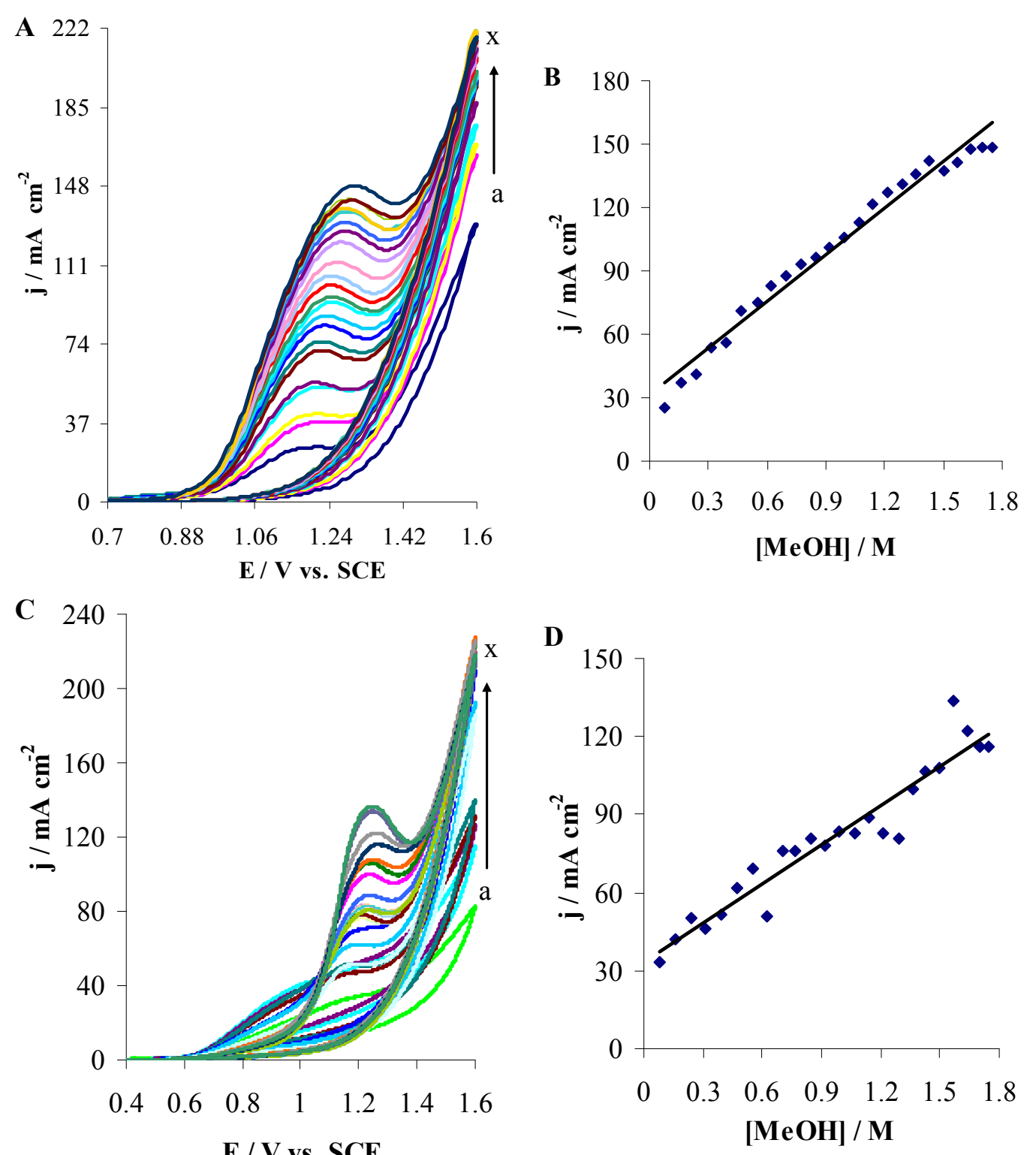

Fig. 4 Cyclic voltammograms for methanol oxidation on (A, B) GC-LaFNPs and (C, D) GC-LaFNPs-CNTs in 1.5 M NaOH in different concentrations of methanol: a) 0.08 , b) 0.16 , c) 0.24 , d) 0.31 , e) 0.39, f) 0.47, g) 0.55, h) 0.62 , i) 0.70, j) 0.77 , k) 0.85 , l) 0.92, m) 0.99 , n) 1.07, o) 1.14 , p) 1.21 , q) 1.29 , r) 1.36 , s) 1.43 , t) 1.50 , u) 1.57 , v) 1.64 , w) 1.70 , x) 1.75 M.

as the optimum concentration. When the methanol concentration increased from 0.08 to $1.75 \mathrm{M}, \mathrm{E}_{\mathrm{f}}$ shifted toward positive direction from 1.17 to $1.3 \mathrm{~V}$. It seemed that the shift of potential to more positive ones was due to the increase in the poisoning rate of the catalyst with increasing the methanol concentration [34]. The effect of methanol concentration on the anodic current density of methanol oxidation on GC/LaFNPs-CNTs electrode was shown in Fig. 4C and $4 \mathrm{D}$. As seen in Fig. $4 \mathrm{C}$ and $4 \mathrm{D}$, when the methanol concentration increased from 0.08 to $1.75 \mathrm{M}$, the current density of methanol oxidation increased from 32.93 to $133.87 \mathrm{~mA} \mathrm{~cm}^{-2}$ and $\mathrm{E}_{\mathrm{f}}$ shifted toward positive direction from 1.16 to $1.269 \mathrm{~V}$. The shift of the anodic peak potential toward the positive potentials was due to the increasing of the methanol concentration and thus increasing of the poisoning rate of the catalyst.

\subsubsection{Effect of LaFNPs Amounts}

The effect of LaFNPs amounts on the anodic 
current of methanol oxidation at GC-LaFNPs electrode was investigated by cyclic voltammetry and chronoamperometry in $1.75 \mathrm{M}$ of methanol and $1.5 \mathrm{M}$ $\mathrm{NaOH}$ (Fig. 5). Different concentrations of LaFNPs (8, 16 and $32 \mathrm{mM}$ ) were used. The anodic peak potentials were observed at 1.36, 1.3, 1.39 V respectively and the current densities of methanol oxidation peaks for 8 , 16 and $32 \mathrm{mM}$ of LaFNPs nanocatalyst were 162.39, 149.99, $108.56 \mathrm{~mA} \mathrm{~cm}^{-2}$ respectively (Fig. 5A). The best catalytic activity of $\mathrm{LaFeO}_{3}$ nanocatalyst toward methanol oxidation was obtained in $\mathrm{LaFeO}_{3} 16 \mathrm{mM}$. This concentration of LaFNPs nanocomposite was selected as the optimum concentration with respect to the anodic peak potential and the current density of methanol oxidation peak. The effect of LaFNPs amount was also determined by chronoamperometry at Fig. 5B. The curve of current density vs. time was obtained at constant methanol oxidation potential (1.1 $\mathrm{V})$ and constant concentration of methanol $(1.75 \mathrm{M})$. As seen in Fig. 5B, there was an initial decay in the current density, and then it became stable. GC/LaFNPs electrode with $2 \mathrm{mg}$ of $\mathrm{LaFeO}_{3}$ had the best catalytic activity toward methanol oxidation in comparison to 1 and $4 \mathrm{mg}$ of the catalyst. Also the catalytic activity of $\mathrm{LaFeO}_{3}$ and $\mathrm{LaFeO}_{3}-\mathrm{CNTs}$ nanocatalysts toward methanol oxidation were compared with each other by chronoamperometry at Fig. 5C. As seen, LaFNPs-CNTs (2 mg LaFNPs and 1 mg CNT) nanocatalyst had better catalytic activity for methanol oxidation than $\mathrm{LaFeO}_{3}$ nanocatalyst. As observed, GC/LaFNPs-CNTs electrode had lower initial decay than GC/LaFNPs electrode showing the lower rate of deactivation of GC/LaFNPs-CNT electrode. Lower rate of deactivation of GC/LaFNPs-CNTs electrode showed that this electrode can probably remove the poisoning intermediates on its surface.

3.4.3 Effect of Sodium Hydroxide Concentration

In order to investigate the effect of $\mathrm{NaOH}$ concentration on the anodic current density $\left(\mathrm{j}_{\mathrm{f}}\right)$ and potential $\left(\mathrm{E}_{\mathrm{f}}\right)$ of the methanol electrooxidation at
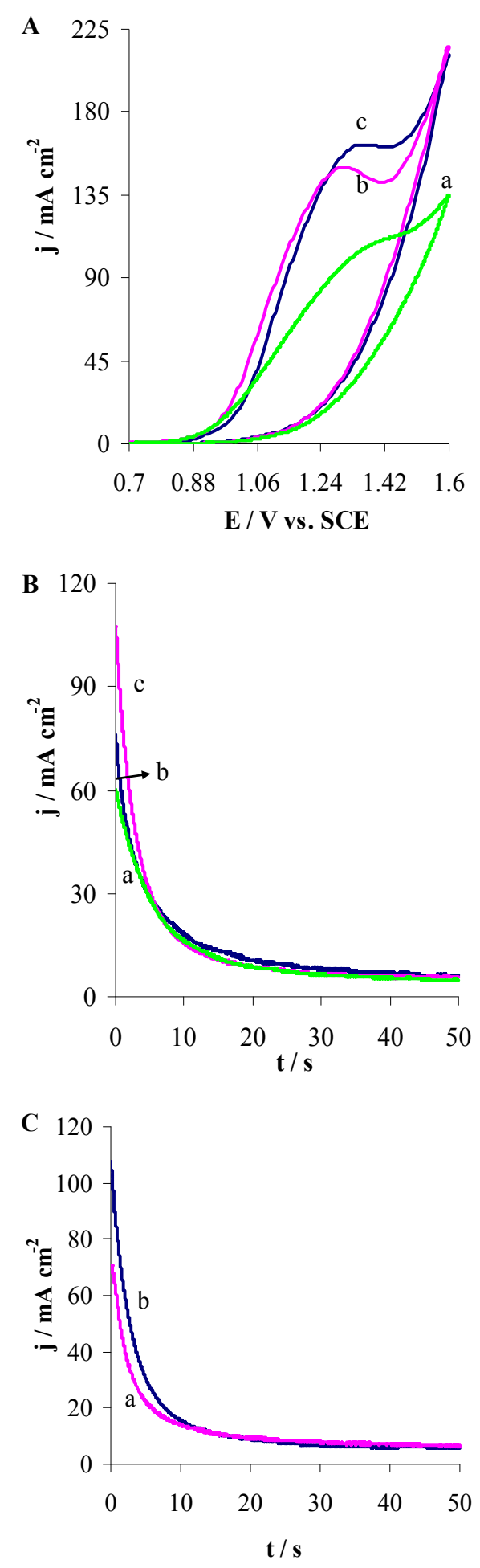

Fig. 5 (A) Cyclic voltammograms; (B) chronoamperograms of methanol oxidation at GC-LaFNPs electrode with different amounts of LaFNPs: a) 1, b) 2, c) 4 mg; (C) chronoamperograms of a) LaFNPs and b) LaFNPs-CNTs nanocatalysts with $2 \mathrm{mg}$ of LaFNPs and 1 mg CNTs in 1.5 $\mathrm{M} \mathrm{NaOH}$ and 1.75 $\mathrm{M}$ methanol. 

Methanol Oxidation in Alkaline Solutions
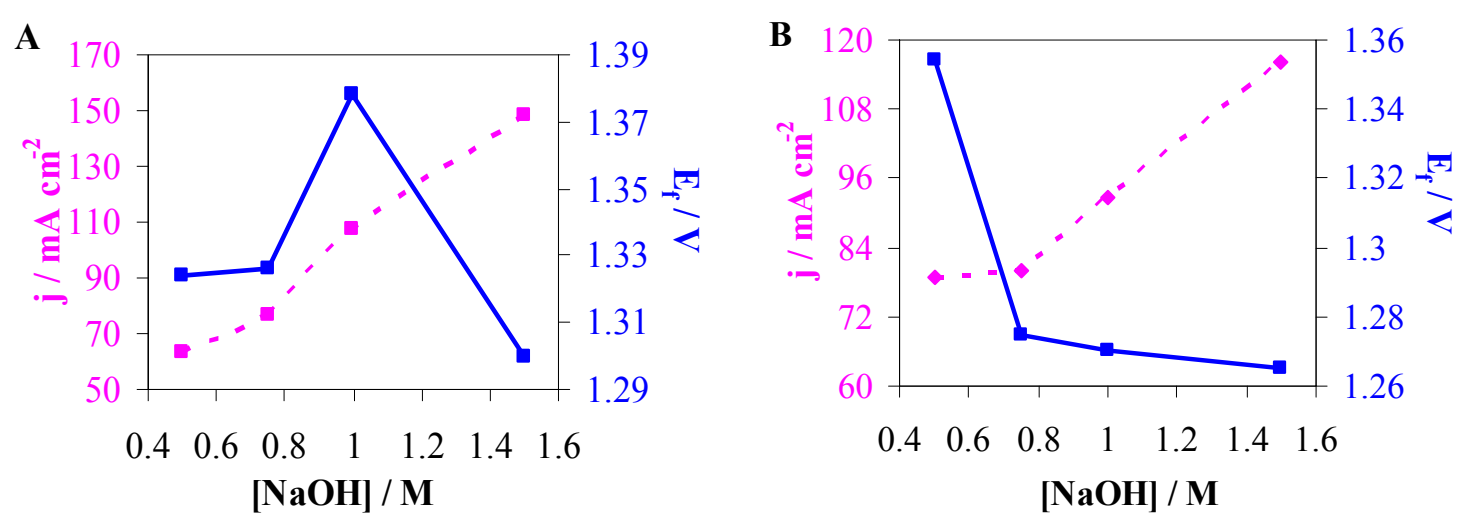

Fig. 6 Effect of $\mathrm{NaOH}$ concentration on the anodic peak current density and potential of methanol electrooxidation at GC/LaFNPs and GC/LaFNPs-CNTs electrodes.
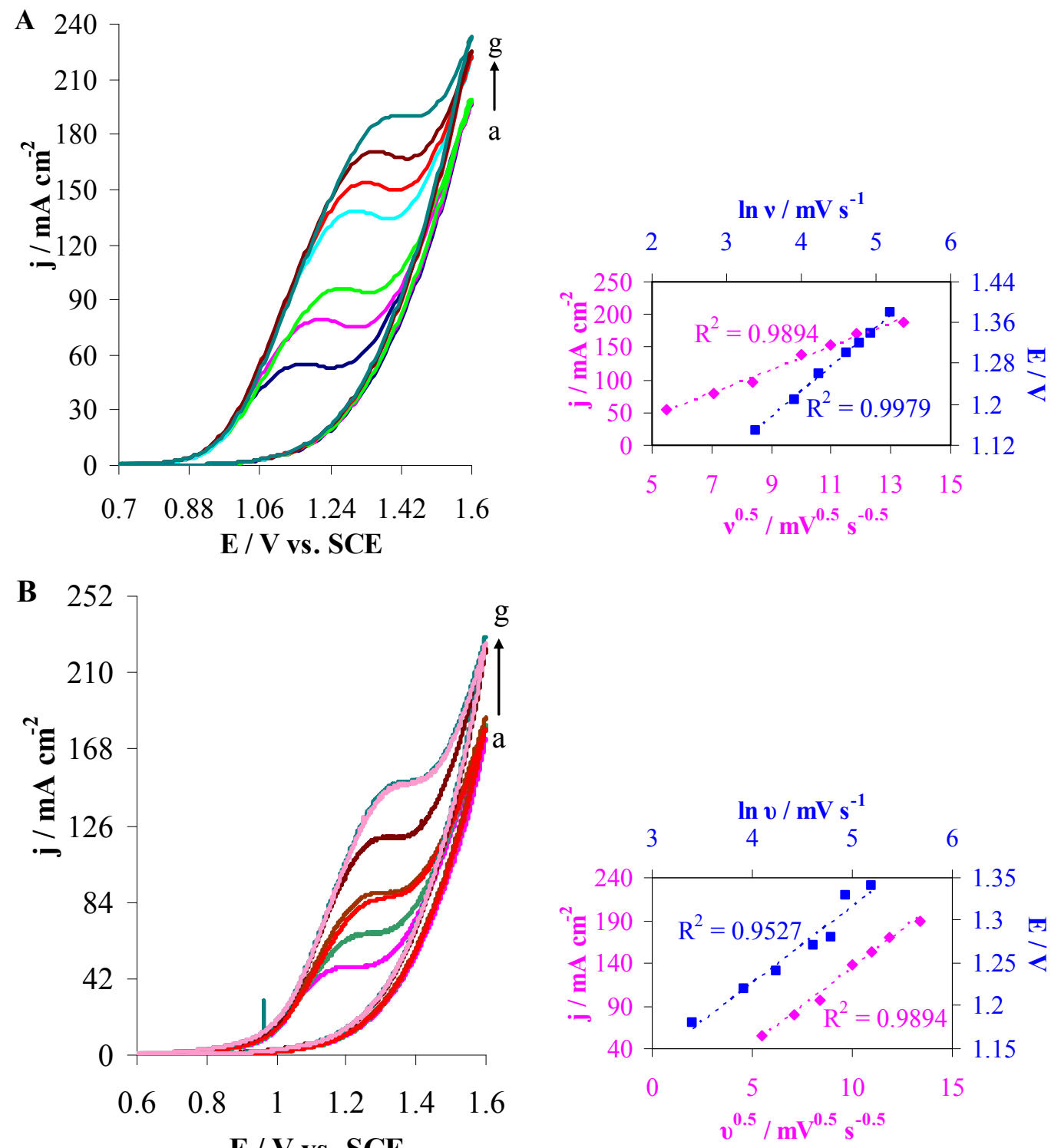

Fig. 7 Anodic current density (j) vs. square root of scan rate $\left(v^{0.5}\right)$ and the plot showing peak potential (E) vs. In $v$ for (A) GC/LaFNPs and (B) GC/LaFNPs-CNTs electrodes in $1.5 \mathrm{M} \mathrm{NaOH}$ and $1.75 \mathrm{M} \mathrm{CH}_{3} \mathrm{OH}$ at the scan rates of 30, 50, 70, 100, 120,140 and $180 \mathrm{mV} \mathrm{s}^{-1}$. 
GC/LaFNPs (Fig. 6A) and GC/LaFNPs-CNTs (Fig. 6B) electrodes, the experiments have been done in different concentrations of $\mathrm{NaOH}(0.5,0.75,1$ and 1.5 M). As seen in Fig. 6A and 6B, the best catalytic activity of as prepared electrodes toward methanol oxidation was obtained in $\mathrm{NaOH}$ 1.5 M., so the experiments were done in this concentration of sodium hydroxide.

\subsubsection{Effect of Scan Rate}

Cyclic voltammograms of methanol oxidation on GC/LaFNPs and GC/LaFNPs-CNTs electrodes at different scan rates $(v)$ in the range of 30 to $180 \mathrm{mVs}^{-1}$ were studied in Fig. 7A and Fig. 7B, respectively. As observed in Fig. 7A and 7B, the anodic current density of methanol oxidation on GC/LaFNPs and GC/LaFNPs-CNTs electrodes increases with increasing of the scan rates. It can be also seen that there was a linear correlation $\left(\mathrm{R}^{2}=0.98\right)$ between the anodic current density and $v^{1 / 2}$, indicating that the kinetics of the overall process is controlled by mass-transport. The peak potential of methanol oxidation (E) amplifies with increasing the scan rate and a linear relationship $\left(\mathrm{R}^{2}=\right.$ 0.95-0.99) has been obtained between $\mathrm{E}$ and $\ln (\mathrm{v})$. This shows that the methanol oxidation is an irreversible charge transfer process. The plot of $E_{p}$ and $\ln (v)$ was a straight line with a slope [35]:

$$
\frac{\delta E_{p}}{\delta(\ln v)}=\frac{R T}{(1-\alpha) \times n F}
$$

In this formula, $\alpha$ is the electron transfer coefficient. It characterizes the effect of electrochemical potential on the activation energy of an electrochemical reaction. The slope of $E_{p}$ vs. $\ln (v)$ plot was 0.13 and $0.09 \mathrm{~V}$ for $\mathrm{GC} / \mathrm{LaFNPs}$ and GC/LaFNPs-CNTs electrodes, respectively. $\alpha$ value was calculated as 0.97 and 0.95 ( $\mathrm{n}=6$ and $\mathrm{T}=20{ }^{\circ} \mathrm{C}$ ) for $\mathrm{GC} / \mathrm{LaFeO}_{3} \mathrm{NPs}$ and $\mathrm{GC} / \mathrm{LaFeO}_{3} \mathrm{NPs}-\mathrm{CNTs}$ electrodes, respectively which is close to 1 . This indicates that the methanol oxidation has super kinetics.

\section{Conclusions}

The study has shown that LaFNPs and
LaFNPs-CNTs electrodes are quite active anodes for methanol electrooxidation in alkaline medium. It has also demonstrated that the electrocatalytic activities of LaFNPs electrodes for methanol oxidation in alkaline solutions are greatly enhanced in the presence of carbon nanotubes. This result was obtained due to the lower onset potential and lower anodic peak potential of LaFNPs-CNTs nanocatalyst than LaFNPs nanocatalyst for methanol oxidation.

\section{References}

[1] Song, Y. J., Han, S. B., and Park, K. W. 2010. "Pt Nanowire Electrodes Electrodeposited in PVP for Methanol Electrooxidation.” Mater. Lett. 64: 1981-4.

[2] Selvaraj, V., and Alagar, M. 2007. "Pt and Pt-Ru Nanoparticles Decorated Polypyrrole/Multiwalled Carbon Nanotubes and Their Catalytic Activity towards Methanol Oxidation." Electrochem. Commun. 9: 1145-53.

[3] Xu, Ch., Tian, Zh., Shen, P., and Jiang, S. P. 2008. "Oxide $\left(\mathrm{CeO}_{2}, \mathrm{NiO}, \mathrm{Co}_{3} \mathrm{O}_{4}\right.$ and $\left.\mathrm{Mn}_{3} \mathrm{O}_{4}\right)$-Promoted $\mathrm{Pd} / \mathrm{C}$ Electrocatalysts for Alcohol Electrooxidation in Alkaline Media." Electrochim. Acta 53: 2610-8.

[4] Singh, R. N., Sharma, T., Singh, A., Anindita, Mishra, D., and Tiwari, S. K. 2008. "Perovskite-Type $\mathrm{La}_{2-x} \mathrm{Sr}_{x} \mathrm{NiO}_{4}(0 \leq x \leq 1)$ as Active Anode Materials for Methanol Oxidation in Alkaline Solutions." Electrochim. Acta 53: 2322-30.

[5] Deshpande, K., Mukasyan, A., and Varma, A. 2006. "High Throughput Evaluation of Perovskite-Based Anode Catalysts for Direct Methanol Fuel Cells." $J$. Power Sources 158: 60-8.

[6] Li, C. L., and Lin, Y. C. 2011. "Methanol Partial Oxidation over Palladium-, Platinum-, and Rhodium-Integrated $\mathrm{LaMnO}_{3}$ Perovskites." Appl. Catal. B. Environ. 107: 284-93.

[7] Li, C. L., Jiang, B. S., Fanchiang, W. L., and Lin, Y. C. 2011. "The Effect of $\mathrm{Pd}$ Content in $\mathrm{LaMnO}_{3}$ for Methanol Partial Oxidation." Catal. Commun. 16: 165-9.

[8] Isupova, L. A., Yakovleva, I. S., Rogov, V. A., Alikina, G. M., and Sadykov, V. A. 2004. "Oxygen States in Oxides with a Perovskite Structure and Their Catalytic Activity in Complete Oxidation Reactions: System La1 $-x \mathrm{Ca} x \mathrm{FeO} 3-y(x=0-1) . "$ Kinet. Catal. 45: 446-53.

[9] Yakovleva, I. S., Nadeev, A. N., Gerasimov, E. Y., Ivanov, D. V., Dovlitova, L. S., Sutormina, E. F., Saputina, N. F., Litvak, G. S., and Isupova, L. A. 2013. "Microwave Synthesis of LaMO3 ( $=$ Mn, Co, Fe) 
Perovskites from Crystalline Hydrates of Nitrates." Kinet. Catal. 54: 119-29.

[10] Bartolomeo, E. D., Traversa, E., Baroncini, M., Kotzeva, V., and Kumar, R. V. 2000. "Solid State Ceramic Gas Sensors Based on Interfacing Ionic Conductors with Semiconducting Oxides.” J. Eur. Ceram. Soc. 20: 2691-9.

[11] White, J. H., and Sammells, A. F. 1993. "Perovskite Anode Electrocatalysis for Direct Methanol Fuel Cells.” J. Electrochem. Soc. 140: 2167-77.

[12] Balasubramanian, A., Karthikeyan, N., and Giridhar, V. V. 2008. "Synthesis and Characterization of $\mathrm{LaNiO}_{3}$-Based Platinum Catalyst for Methanol Oxidation.” J. Power Sources 185: 670-5.

[13] Ladavos, A. K., and Pomonis, P. J. 1991. "Comparative Study of the Solid-State and Catalytic Properties of La2-xSrxNiO4 $\lambda$ Perovskites $(x=0.00-1.50)$ Prepared by the Nitrate and Citrate Methods." J. Chem. Soc. Faraday Trans. 87: 3291-7.

[14] Voorhoeve, R. J. H., Johnson, D. W., Remeika, J. P., and Gallagher, P. K. 1977. "Perovskite Oxides: Materials Science in Catalysis." Science 195: 827-33.

[15] Yu, N., Kuai, L., Wang, Q., and Geng, B. 2012. "Pt Nanoparticles Residing in the Pores of Porous $\mathrm{LaNiO}_{3}$ Nanocubes as High-Efficiency Electrocatalyst for Direct Methanol Fuel Cells." Nanoscale 4: 5386-93.

[16] Bockris, J. O. M., and Minevski, Z. S. 1994. "Electrocatalysis: Past, Present and Future." Electrochim. Acta 39: 1471-9.

[17] White, J. H., and Sammells, A. F. 1993. "Perovskite Anode Electrocatalysis for Direct Methanol Fuel Cells." J. Electrochem. Soc. 140: 2167-77.

[18] Lan, A., and Mukasyan, A. S. 2008. "Complex $\mathrm{SrRuO}_{3}-\mathrm{Pt}$ and $\mathrm{LaRuO}_{3}-\mathrm{Pt}$ Catalysts for Direct Alcohol Fuel Cells.” Ind. Eng. Chem. Res. 47: 8989-94.

[19] Jiang, Z., Jiang, Z., and Meng, Y. 2011. "High Catalytic Performance of Pt Nanoparticles on Plasma Treated Carbon Nanotubes for Electrooxidation of Ethanol in a Basic Solution." Appl. Surf. Sci. 257: 2923-8.

[20] Zhao, Y., Yang, X., and Tian, J. 2009. "Electrocatalytic Oxidation of Methanol at 2-aminophenoxazin-3-one-functionalized Multiwalled Carbon Nanotubes Supported PtRu Nanoparticles." Electrochim. Acta 54: 7114-20.

[21] Ye, W., Hu, H., Zhang, H., Zhou, F., and Liu, W. 2010. "Multi-walled Carbon Nanotube Supported Pd and Pt Nanoparticles with High Solution Affinity for Effective Electrocatalysis.” Appl. Surf. Sci. 256: 6723-8.

[22] Khorasani-Motlagh, M., Noroozifar, M., Yousefi, M., and Jahani, Sh. 2013. "Chemical Synthesis and
Characterization of Perovskite NdfeO3 Nanocrystals via a Co-Precipitation Method." Int. J. Nanosci. Nanotechnol. 9: 7-14.

[23] Noroozifar, M., Khorasani-Motlagh, M., Khaleghian-Moghadam, R., Ekrami-Kakhki, M. S., and Shahraki, M. 2013. "Incorporation Effect of Nanosized Perovskite $\mathrm{LaFe}_{0.7} \mathrm{Co}_{0.3} \mathrm{O}_{3}$ on the Electrochemical Activity of Pt Nanoparticles-multi Walled Carbon Nanotube Composite toward Methanol Oxidation." J. Solid State Chem. 201: 41-7.

[24] Yu, H. Ch., Fung, K. Z., Guo, T. Ch., and Chang, W. L. 2004. "Syntheses of Perovskite Oxides Nanoparticles $\mathrm{La}_{1-x} \mathrm{Sr}_{x} \mathrm{MO}_{3-\delta} \quad(\mathrm{M}=\mathrm{Co}$ and $\mathrm{Cu})$ as Anode Electrocatalyst for Direct Methanol Fuel Cell." Electrochim. Acta 50: 811-6.

[25] Raghuveer, V., Thampi, K. R., Xanthopoulos, N., Mathieu, H. J., and Viswanathan, B. 2001. "Rare Earth Cuprates as Electrocatalysts for Methanol Oxidation." Solid State Ionics 140: 263-74.

[26] Raghuveer, V., and Viswanathan, B. 2002. "Can $\mathrm{La}_{2-\mathrm{x}} \mathrm{Sr}_{\mathrm{x}} \mathrm{CuO}_{4}$ Be Used as Anodes for Direct Methanol Fuel Cells?" Fuel 81: 2191-7.

[27] Singh, R. N., Singh, A., Mishra, D., Anindita, and Chartier, P. 2008. "Oxidation of Methanol on Perovskite-Type $\mathrm{La}_{2-\mathrm{x}} \mathrm{Sr}_{\mathrm{x}} \mathrm{NiO}_{4}(0 \leq \mathrm{x} \leq 1)$ Film Electrodes Modified by Dispersed Nickel in 1M KOH." J. Power Sources 185: 776-83.

[28] Lamy, C., Lima, A., LeRhun, V., Delime, F., Coutanceau, C., and Léger, J.-M. 2002. "Recent Advances in the Development of Direct Alcohol Fuel Cells (DAFC).” J. Power Sources 105: 283-96.

[29] Leger, J. M. 2005. "Preparation and Activity of Monoor Bi-metallic Nanoparticles for Electrocatalytic Reactions." Electrochim. Acta 50: 3123-9.

[30] Lan, A., and Mukasyan, A. S. 2007. "Perovskite-Based Catalysts for Direct Methanol Fuel Cells." J. Phys. Chem. C. 111: 9573-82.

[31] Rios, E., Gautier, J.-L., Poillerat, G., and Chartier, P. 1998. "Mixed Valency Spinel Oxides of Transition Metals and Electrocatalysis: Case of the $\mathrm{Mn}_{\mathrm{x}} \mathrm{Co}_{3-\mathrm{x}} \mathrm{O}_{4}$ System." Electrochim. Acta 44: 1491-7.

[32] Bockris, J. O. M., and Otagawa, T. 1984. "The Electrocatalysis of Oxygen Evolution on Perovskites." J. Electrochem. Soc. 131: 290-302.

[33] Daghetti, A., Lodi, G., and Trasatti, S. 1983. "Interfacial Properties of Oxides Used as Anodes in the Electrochemical Technology." Mater. Chem. Phys. 8: 1-90.

[34] Ekrami-Kakhki, M. S., Khorasani-Motlagh, M., and Noroozifar, M. 2011. "Platinum Nanoparticles Self-assembled onto Chitosan Membrane as Anode for Direct Methanol Fuel Cell." J. Appl. Electrochem. 41: 
Perovskite-Type $\mathrm{LaFeO}_{3}$ and $\mathrm{LaFeO}_{3}$-CNTs Nanocrystals as Active Anode for Methanol Oxidation in Alkaline Solutions

$527-34$.

[35] Tong, H., Li, H. L., and Zhang, X. G. 2007. "Ultrasonic Synthesis of Highly Dispersed Pt Nanoparticles
Supported on MWCNTs and Their Electrocatalytic Activity towards Methanol Oxidation." Carbon 45: 2424-32. 